\title{
Information System Performance in Digitalization Era
}

\author{
${ }^{1}$ Seow Chee Hsin and ${ }^{2}$ Heng Meng \\ ${ }^{1,2}$ Nottingham University Business School, University of Nottingham Malaysia, Malaysia \\ ${ }^{1}$ cheehsin@nottingham.edu.my
}

\begin{abstract}
Article Info
Journal of Journal of Enterprise and Business Intelligence (http://anapub.co.ke/journals/jebi/jebi.html)

Doi: https://doi.org/10.53759/5181/JEBI202101018
\end{abstract}

Received 15 April 2021; Revised form 12 July 2021; Accepted 22 August 2021.

Available online 05 October 2021.

(C2021 Published by AnaPub Publications.

\begin{abstract}
During a pandemic like now, digitization and the police have become a continuous collaboration The importance of the existence of the police is increasingly needed by a society that is increasingly developing and facing increasing social problems. The traffic police unit for the city of Samarinda is a special unit that is generally involved in the field of vehicle discipline, in that it is always ready to serve the community, especially during the pandemic. For services provided to the community, of course, not all can be covered well, given the situation and conditions of the regions that are experiencing rapid development. Thus, the importance of fulfilling the internal factors of optimal human resources in the traffic unit of the Samarinda Police also needs attention. Through the use of leadership style variables, organizational learning, and job satisfaction, then it will be meas ured the individual performance achievement which is also the performance of the organization. Respondents taken in the sample of this study were the entire population of members of the Samarinda Traffic Police, totaling 108 members. The use of questionnaire media is a measuring tool used in further analysis in the SEM PLS model to answer the research hypothesis. Thus, it is therefore more relevant to the use of the conceptual model of investigating the relationship between constructs using confirmatory factor analysis (CFA). This study also contains a discussion of the theory and results of empirical studies.
\end{abstract}

Keywords - Leadership Style, Organization Culture, Job Satisfaction, Job Performance.

\section{INTRODUCTION}

Traffic and Road Transportation (LLAJ) is important in increasing the social mobility of the community, having a role as a media liaison for the community in interacting and moving places to run the economy. Almost every time people carry out activities from time to time, people continue to use road transportation with various interests. The history of road traffic and transportation in Indonesia has gone through various periods from the time of Dutch rule to the current reform era. Traffic and road transportation have also gone through various conditions of the era accompanied by various advances in the fields of science and technology to changes in people's behavior patterns.

Considering that the function of road traffic and transportation is a means of moving from one place to another, it is only right that traffic is the most important thing in the life of a country's development, namely the Republic of Indonesia. Because traffic has a strategic role in supporting national development and integration as part of efforts to advance welfare. Road traffic and transportation must develop their potential and role to realize security, welfare, traffic order, and road transportation in the framework of supporting economic development and regional autonomy, as well as the accountability of state administration as stipulated in [1] concerning traffic. and road transportation, in the DPR RI Plenary Meeting on 26 May 2009 which was later ratified by the President of the Republic of Indonesia on 22 June 2009 which is a continuation of [5].

The phenomenon of violations of traffic and road transportation that often occurs in a situation where there is a mismatch between regulations and implementation. The rules in this case are legal instruments that have been established and agreed upon by the state as laws that apply legally, while the implementation is human beings or the people of a country who are bound by these legal instruments. The majority of traffic violations are in the form of violations of traffic signs and traffic lights, such as prohibitions on stopping and parking in certain places, running traffic lights, and others. This cannot be ignored because most accidents are caused by traffic violations.

The regulation is made by the government regarding every road user, where every individual is expected to be able to implement regulations in traffic, including whoever they are, including pedestrians, two-wheeler riders, and fourwheeled drivers. One of the causes of the high number of traffic accidents is the lack of public awareness in driving, for example not paying attention to and obeying existing traffic regulations, not having mental readiness when driving, 
or driving exhausted. The condition of the driver's unpreparedness in driving allows accidents that can endanger the safety of other road users. Apart from the causes of traffic accidents described above, the occurrence of traffic accidents on the road is also influenced by the age of the driver himself. In achieving the goal of safe, secure, orderly, and smooth traffic services to the public using transportation modes, especially land transportation, it requires excellent performance from officers who have the authority, in this case, the ranks of the police officers of the Republic of Indonesia, especially traffic units. Assessment of the concept of police performance is very important, this is because the police performance assessment is a holistic assessment, on the activities of the police apparatus providing services to the public, this is also conveyed by [16], that the concept of police performance is important because it is a holistic index of how well the police provide services to the public. Police performance appraisals can be carried out through a variety of methods. The most common method of police assessment is through measures such as crime rate, detention, cases charged in court, indictments received. Official crime data issues range from nonreporting to underreporting, to record-keeping bias, and conceptual and methodological issues.

The management and performance monitoring system in the police apparatus still emphasizes compliance, as stated by [6], [20] that traditional police management and supervision emphasize compliance through the doctrine of command and control, "means to an end". The problem that often arises is that the leadership style in the traffic unit of the Samarinda City Police uses an autocratic style which causes the performance of subordinates to be disturbeod so that subordinates who work feel depressed and are less motivated to work. Another problem factor that can affect employee performance is the motivation of the Samarinda City Police traffic unit's absence of attention to their subordinates and considers that they are not merely subordinates and morale has decreased drastically at this time.

\section{LITERATURE REVIEW}

\section{Organizational Culture (Organization Culture)}

In the environment of an organization, whether it is a profit organization or a non-profit organization, a work pattern is created that results from daily work routines and becomes a culture of the organization. This is according to what was stated by [4], who views organizational culture as a pattern of basic assumptions that are shared in an organization, especially in solving the problems at hand. These patterns become something certain and socialized to new members of the organization. The understanding of the members of an organization of the existing system in the organization becomes a perception of being a system after being interpreted by members of the organization. This is by the opinion of [18], that the notion of organizational culture is a shared meaning system adopted by members that distinguish an organization from other organizations. This system of shared meaning, on closer inspection, is a set of key characteristics valued by an organization. Organizational culture is concerned with how employees perceive the characteristics of organizational culture, not whether employees like the culture or not. A similar opinion is expressed by [14], who argues that organizational culture is "the personality of the organization: the shared beliefs, values, and behaviors of the group. It is symbolic, holistic, and unifying, stable, and difficult to change".

Culture is not clear behavior or things that a person can see and observe. Culture is also not a philosophy or value system that is pronounced or written in the organization's statutes but culture is an assumption that lies behind values and determines individual behavior patterns towards organizational values, organizational atmosphere, and leadership [6]. Organizations with certain cultures provide an attraction for individuals with certain characteristics to join. Organizational culture is a common pattern of assumptions learned by the group when solving problems of external adaptation and internal integration that have functioned well enough to be correct and to be taught to new group members as the correct way to accept, think and feel. About these problems [2]. According to the opinion [15] in an article entitled Dimensionalizing Cultures: The Hofstede Model in Context, stated in his research that 5 characteristic models have been successfully identified to measure culture in a cross-country society.

\section{Style of Leadership (Leadership Style)}

Leadership involves a process of influence that is concerned with facilitating the performance of shared tasks. Otherwise, the definition of leadership differs in various aspects, such as who exerts influence, the result of the influence. Leadership as the ability to influence a group towards achieving goals. The source of this influence can be formal, such as that provided by the ownership of managerial ranks in an organization [2]. Since management positions arise with a formally designated level of authority, a person can assume a leadership role solely because of his position in the organization. But not all leaders are managers and vice versa, not all managers are leaders. Just because an organization grants its managers certain formal rights is not a guarantee that they will be able to lead effectively. It is often found that unsupported leadership is the ability to influence what arises outside the formal structure of the organization, which is equal to or more important than formal influence. Leadership is the attitude and behavior to influence subordinates so that they can work together to form a working relationship. Harmony to achieve efficiency and effectiveness to achieve the level of productivity as determined. 
It is also stated that leadership is the ability to influence a group to achieve a vision or goal. Leadership is one and three activities in the act of supervision [19]. Furthermore, it is stated as follows: leadership style consists of a combination of task behavior and relationship behavior. Task behavior is intended as a level of leader's effort to organize and determine the role of group members (followers), explain each activity and when, where, and how to complete it; characterized by efforts to establish organizational patterns, communication channels, and a detailed and clear way of completing work [8]. Meanwhile, relationship behavior is the level of effort of leaders to foster personal relationships among themselves and with their group members (followers) by opening wide channels of communication and providing socio-emotional psychological support and ease of behavior. A leader in leadership will be judged by the surrounding environment, including his colleagues or subordinates, and a great leader will be born if his colleagues and subordinates work well as well.

Leadership style is a behavior norm that is used by someone when trying to influence the behavior of others or subordinates. Leaders cannot use the same leadership style in leading their subordinates but must be adjusted to the characteristics of the ability level in the duties of each subordinate. Next, the notion of leadership as behavior was put forward by [13] that leadership involves a set of interpersonal influence processes. The processes are aimed at motivating subordinates, creating a vision for the future, and developing strategies for achieving goals.

Transformational leadership is a condition in which the followers of a transformational leader feel their trust, admiration, loyalty, and respect for the leader, and they are motivated to do more than what they initially expected. In this situation, the leader transforms and motivates his followers by making them more aware of the importance of the results of a job, encouraging them to place more importance on the organization or team than their interests, and activate their needs at a higher level. It was also explained that transactional leadership theory is a management theory whose study focuses on the role of supervision, organization, and group performance [2]. This theory uses a transaction approach to be mutually agreed between leaders and employees. The leader takes the initiative to offer a form of satisfaction for the employees below him in the form of wages and promotions, and if an agreement has been made, then the leader follows up by formulating and describing tasks clearly and operationally explaining targets, and motivating employees to work hard. This theory also uses the principle of punishment and reward.

\section{Job Satisfaction (Job Satisfaction)}

In [2] based on the results of his research states that job satisfaction is multidimensional, where a person feels more or less satisfied with his job, supervisor, workplace, and so on. According to [10] as well as in opinion, a diagram of job satisfaction depicts job satisfaction as people's emotional response to job conditions. Job satisfaction is multidimensional so job satisfaction can represent overall or general satisfaction or refer to the section someone's job. This means that in general, it reflects very high satisfaction, but someone may feel dissatisfied with one or several aspects, such as vacation schedules [17].

According to the opinion [4], job satisfaction can be defined as the feelings and reactions of individuals to their work environment. According to this approach, although job satisfaction is under the influence of many external factors, it remains something internal that has to do with the way how the employee feels. That is job satisfaction presents a set of factors that cause a feeling of satisfaction. Similarly, according to [1] states that job satisfaction is: job satisfaction is defined as the positive feeling about one's job resulting from an evaluation of its characteristics. Is has been defined differently by various scholars. As a general attitude of an individual towards his job. Work requires interaction with coworkers and superiors to follow organizational rules and policies, meet work performance standards, live in working conditions that are often less than ideal, and other similar things Job satisfaction is a positive emotional state of a person that results from an appreciation for a job he has done [11]. Job satisfaction is defined as a general attitude toward one's job, the difference between the amount of reward a worker receives, and the amount they believe they should receive [20].

\section{Performance (Job Performance)}

Employee performance greatly affects the success of an organization's goals, seeing the importance of employees in an organization, this is by the opinion of [9], which states that performance is a behavior or action that is relevant to organizational goals. It can be said that employees are a valuable organizational asset, hence the need for support and development to make employees' abilities good. Performance aspects are as follows: (1) The quantity of work results is the sum of the work completed by the employee; (2) Quality of work is the result of work achieved by an employee following the terms and conditions; (3) Timeliness is the employee's timeliness in completing the work that has been given; (4) Attendance at work is the attendance of employees by the rules or regulations that apply in the organization; damn (5) Cooperative attitude is the attitude of working together well and obeying the applicable regulations in the organization [12]. According to the opinion [7] is the result of the multiplication between motivation and ability or formulated as follows: Performance $=\mathrm{f}$ (motivation $\mathrm{x}$ ability). Employee performance is one of the impacts or 
benchmarks of job satisfaction [19]. Research [1] states that performance is an outcome that is achieved because they are motivated by work and satisfied with the work they do. A person who is satisfied with his job will work more productively and faithfully with his organization, while workers who are not satisfied with their job will work less productively and tend to have the desire to quit their job in research [3]. Subsequent research from [7] shows that job satisfaction is a complex and multifactorial phenomenon, where collaboration between individual employees, superiors, and others is important to increase employee satisfaction with their work. employees are a function of the interaction between ability and motivation [20].

\section{Conceptual Framework and Hypotheses}

After reviewing the literature on organizational culture, leadership style, job satisfaction, and performance, this study is considered to be carried out on all respondents in the staff category so that a conceptual framework for research and the following hypothesis can be designed as shown in figure 1:

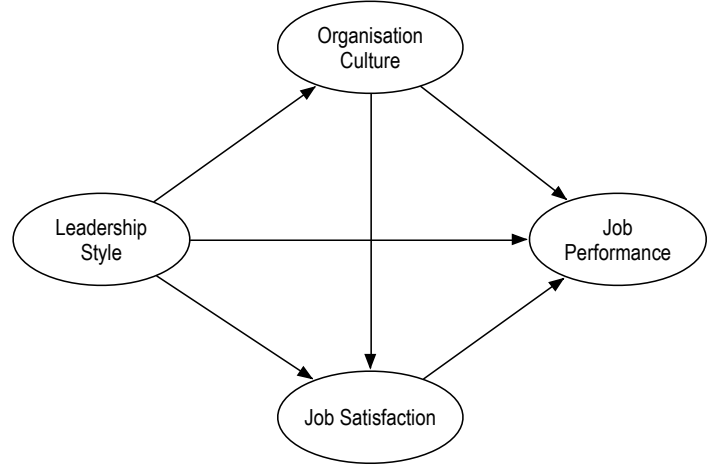

Fig 1: Conceptual Framework

The hypotheses put forward in this study are as follows:

H1 : The higher the level of leadership style, the higher the organization culture

H2 : The higher the level of an organization culture, it will increase job performance

H3 : The higher the level of job satisfaction, the higher the job performance

H4 : The higher the leadership style level, the higher the level job satisfaction

H5 : The higher the leadership style level, the higher the job performance level

H6 : The higher the level of organization culture, the higher the level of job satisfaction

\section{RESEARCH METHODS}

\section{Sampling}

In this study for empirical validation in the research model, sampling was carried out on the entire population of members of the Samarinda Traffic Police, who were active on duty as staff until the end of 2019. The sample number of respondents in this study consisted of 108 respondents as active police on duty in the traffic unit at the Samarinda Police or using a saturated sample.

\section{Data Collection}

The data collection was carried out by distributing a list of questions to all respondents and this was supported, considering that all respondents were in the same office location. Each respondent is asked a question on the three main types of variables used, with each variable having an indicator question that must be answered with the respondent's perception.

\section{Variable Definition and Measurement}

The selection of measuring instruments in this study is carried out carefully, through the support of the literature. Before the distribution of the questionnaire was carried out, the initial testing of the sample of respondents was conducted to determine the initial validity and reliability of the research respondents, so that for the next stage, the questionnaire was feasible to be distributed to all respondents. This study also uses a measurement scale, with a Likert scale with five levels of measurement, ranging from best to very bad. The independent variable, in this case, is as much as 3 variables and determined is the style of leadership, organizational culture, and job satisfaction, while acting as the dependent variable is Performance. Variabel leadership style proxied by 9 indicator variables, organizational culture is proxied by 10 indicator variables, job satisfaction with 8 variable indicators, and performance is proxied by 7 
variable indicators. Thus, all indicators used are 34 variable indicators. The analytical tool used in the measurement is through the structural equation model (SEM) with the support of WarpPLS Version 6.0 software to complete the analysis.

\section{EMPIRICAL RESULTS}

This research is processed using confirmatory techniques so that it follows the validity and reliability requirements of the research construct. The results of the validity analysis show that all research indicators have high validity, as well as reliability testing also shows that all the questions are reliable. Besides, all the loading factor indicator values are above or $>0.70$ or indicate that it is entirely acceptable for research analysis. From the results of the general results, it shows that the model has a fairly good fit, where the P-value for the Average Path Coefficient (APC) $<0.001$ and Average R-squared (ARS) and Average Adjusted R-squared (AARS)> 0, 05 with an APC value $=0.254$, an ARS value $=0.214$ and an AARS value $=0.199$. Likewise, the value of Average block VIF (AVIF) and Average Full Collinearity VIF (AFVIF), which is generated, is $<3.3$ which means that there is no multicollinearity problem between indicators and between exogenous variables. The resulting GoF is $0.305>0.25$, which means that the fit of the model is included in the medium category. For the Simpson's paradox index (SPR), the R-squared contribution ratio (RSCR) and nonlinear bivariate causality direction ratio (NLB CDR) yields a value equal to 1 , which means that there is no causality problem in the model. Meanwhile, the index of statistical suppression ratio (SSR) produces a value of 0.833 > 0.70 which means it is still acceptable. It can also be seen that the number of iterations for this model is done more than 5 times. The results of the analysis output can be shown in the following figure 2 :

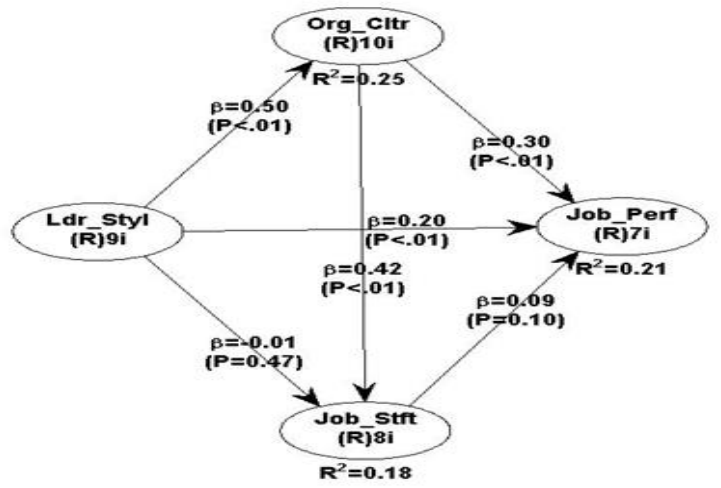

Fig 2: Results of Multiple-Mediator Model Analysis

Based on the results of the path analysis generated in the calculation, it can be shown in the table as follows in table 1:

Table 1: Path Coefficient and $\mathrm{P}_{\text {_Values }}$ (Direct Effect)

\begin{tabular}{|c|c|c|c|c|}
\hline Path Coefficients & Org_Clt & Ldr_Sty & Job_Stf & Job_Per \\
\hline$\overline{\text { Org_Clt }}$ & & 0.501 & & \\
\hline \multicolumn{5}{|l|}{ Ldr_Sty } \\
\hline Job_Stf & 0.420 & -0.005 & & \\
\hline Job_Per & 0.298 & 0.204 & 0.094 & \\
\hline \multicolumn{5}{|l|}{$\underline{P \text { values }}$} \\
\hline Org_Clt & & $<0.001$ & & \\
\hline \multicolumn{5}{|l|}{ Ldr_Sty } \\
\hline Job_Stf & $<0.001$ & 0.472 & & \\
\hline Job_Per & $<0.001$ & 0.003 & 0.104 & \\
\hline
\end{tabular}

Based on table 1, it shows that the influence of leadership style on organizational learning is 0.501 and significant at $<0.001$. Leadership style has an effect on job satisfaction with a regression coefficient of -0.001 and not significant at 0.47 or $>0.05$. Leadership style affects job performance with a regression coefficient of 0.204 and significant at $<0.001$. Organizational culture has an effect on job satisfaction with a regression coefficient of 0.420 or significant at $<0.001$. Organizational culture has an effect on job performance with a regression coefficient of 0.298 or significant at 
$<0.001$. Meanwhile, the effect of job satisfaction on job performance with a regression coefficient of 0.094 or not significant at $0.104>0.05$.

\begin{tabular}{|c|c|c|c|c|}
\hline Indirect effect for Path & Org_Clt & Ldr_Sty & Job_Stf & Job_Per \\
\hline \multicolumn{5}{|l|}{ Org_Clt } \\
\hline \multicolumn{5}{|l|}{ Ldr_Sty } \\
\hline Job_Stf & & 0.211 & & \\
\hline Job_Per & 0.039 & 0.149 & & \\
\hline \multicolumn{5}{|l|}{$P$ values of indirect effect } \\
\hline \multicolumn{5}{|l|}{ Org_Clt } \\
\hline \multicolumn{5}{|l|}{ Ldr_Sty } \\
\hline Job_Stf & & $<0.001$ & & \\
\hline Job_Per & 0.227 & 0.023 & & \\
\hline
\end{tabular}

Based on table 2, shows that leadership style has an indirect effect on job satisfaction through mediating organizational culture with a regression coefficient of 0.211 or significant at $<0.001$. Likewise, leadership style has an indirect effect on job performance through the mediation of organizational culture and job satisfaction with a regression coefficient of 0.149 or significant at $0.023<0.05$. Also, Organizational culture has an indirect effect on job performance through the mediation of organization culture and job satisfaction with a regression coefficient of 0.039 or not significant at $0.227>$ 0.05 .

\begin{tabular}{lllll} 
& Table 3: Latent Variable Coefficients & \\
& Org_Clt & Ldr_Sty & Job_Stf & Job_Per \\
\hline R-squared & 0.251 & & 0.177 & 0.214 \\
Adj. R-squared & 0.244 & & 0.161 & 0.191 \\
Composite reliab. & 0.855 & 0.872 & 0.764 & 0.863 \\
Cronbach's alpha & 0.811 & 0.835 & 0.713 & 0.803 \\
Avg. var. extrac. & 0.597 & 0.562 & 0.571 & 0.509 \\
Full Collin. VIF & 1.460 & 1.264 & 1.169 & 1.262 \\
Q-squared & 0.252 & & 0.192 & 0.228 \\
\hline
\end{tabular}

The adjusted R- the squared coefficient for organizational culture is 0.244 , which means that the organizational culture variable that can be explained by leadership style is $24.4 \%$ and the remaining $75.6 \%$ is explained by other variables outside the model. The adjusted R-squared coefficient for job satisfaction is 0.161 , which means that two variables of leadership style and organizational learning can explain the variation in job satisfaction by $16.1 \%$. Likewise, the Adjusted R-squared for job performance is 0.191 which means leadership style, organizational culture, and job satisfaction can explain job performance variations of $19.1 \%$.

The fourth variable latent have a high level of reliability, it can be seen from the Composite reliability for all of the variables are above or $>0.70$ and likewise with the value of Cronbach's Alpha entirely well above or $>0.70$ thus meeting the internal consistency reliability. Furthermore, the AVE value for all variables is above or>0.50 so that it meets the convergent validity. The Full Collin VIF value for each variable is $<3.3$ so that there are no vertical or lateral collinearity problems in the model. The resulting Q-squared value for each dependent or exogenous variable is $>0$ which indicates that the model has predictive relevance as shown in table 3.

\section{DISCUSSION AND IMPLICATIONS}

This study shows the results that leadership style has a direct and indirect effect on job satisfaction. Also, leadership style has an indirect effect on job performance through the mediation of job satisfaction and organizational learning. Except for the indirect effect of organizational learning on job performance, it cannot be mediated by leadership style and job satisfaction. The results of the study show that leadership style has a positive and significant effect on organizational learning, where the more leadership style increases, the organization culture will also increase. Thus, hypothesis $\mathrm{H} 1$ which has been stated is accepted. This result is in line with the opinion where through leadership styles can make leaders feel confident so that they can gain trust, respect, loyalty and honor from his followers and in the end 
he was able to encourage members of the organization to prioritize the organization more than individual interests. In conditions on the ground, where the Samarinda Police Traffic Unit, the role of the unit head is to play a major role in the success of the organization in this division, and for the police unit, the line of command is firm from the top-down as an order.

Organizational culture has a positive and significant effect on job performance. This also shows that the $\mathrm{H} 2$ hypothesis can be accepted or the more the organization culture increases, the job performance will also increase. This result is also in line with the opinion who views organizational culture as a pattern of basic assumptions that are shared in an organization, especially in solving problems faced, so that the achievement of job performance will be even more real. This is also in line with the opinion where organizational culture does not only like and dislikes or an unwritten order. rigid, but more than that, organizational culture can make a person feel satisfied with his work so that he can get used to working with a fixed pattern to produce high productivity. Likewise, in the Samarinda Police traffic unit, organizational culture can build morale and comfort at work so that it is more motivating to work optimally.

\section{References}

[1]. T. Kono, K. K. Joshi, and Y. Morita, "Floor Area Ratio and Urban Boundary Regulation in Monocentric Cities with Traffic Congestion," SSRN Electronic Journal, 2009.

[2]. D. A. M. Babu, "Study of Congestion Contributors of Traffic Mobility in Urban Areas: A Case Study of Gaddiannaram Municipality Area Hyderabad, A.P., India," International Journal of Scientific Research, vol. 3, no. 6, pp. 137-139, Jun. 2012.

[3]. Z. Wang, "Research and Strategy of Urban Traffic Congestion Control," Urban Transportation \& Construction, vol. 6, no. 2, p. 34, Sep. 2020.

[4]. A. Mohan RAO and K. R. RAO, "Identification Of Traffic Congestion On Urban Arterials For Heterogeneous Traffic," Transport Problems, vol. 11, no. 3, pp. 131-142, 2017.

[5]. P. Cramton, "How Can We Eliminate Traffic Congestion in Urban Centers?," Latest Thinking, 2017.

[6]. Hanseon Cho, 박지형, and 이동민, "Development of the Estimation Method of Traffic Congestion Costs for Highways in Urban Area," Journal of Transport Research, vol. 16, no. 1, pp. 31-44, Mar. 2009.

[7]. M. Khelf and S. Boukebbab, "The effect of noise on the comfort of passengers inside the tramway and its impact on traffic congestion in the urban area," Journal of Vibroengineering, vol. 20, no. 1, pp. 530-540, Feb. 2018.

[8]. E. Safirova, "Telecommuting, traffic congestion, and agglomeration: a general equilibrium model," Journal of Urban Economics, vol. 52, no. 1, pp. 26-52, Jul. 2002.

[9]. E. T. Verhoef and J. Rouwendal, "A behavioural model of traffic congestion," Journal of Urban Economics, vol. 56, no. 3, pp. 408434, Nov. 2004.

[10]. A. Mohan Rao and K. Ramachandra Rao, "MEASURING URBAN TRAFFIC CONGESTION - A REVIEW," International Journal for Traffic and Transport Engineering, vol. 2, no. 4, pp. 286-305, Dec. 2012.

[11]. A.K. Tang, "The Cost of Traffic: Evidence from the London Congestion Charge," Journal of Urban Economics, vol. 121, p. 103302, Jan. 2021.

[12]. K. Hymel, "Does traffic congestion reduce employment growth?," Journal of Urban Economics, vol. 65, no. 2, pp. 127-135, Mar. 2009.

[13]. R. Arnott and E. Inci, "The stability of downtown parking and traffic congestion," Journal of Urban Economics, vol. 68, no. 3, pp. 260-276, Nov. 2010.

[14]. T. Tsekeris and N. Geroliminis, "City size, network structure and traffic congestion," Journal of Urban Economics, vol. 76, pp. 1-14, Jul. 2013.

[15]. M. Kohan and J. M. Ale, "Discovering traffic congestion through traffic flow patterns generated by moving object trajectories," Computers, Environment and Urban Systems, vol. 80, p. 101426, Mar. 2020.

[16]. E. Zhang, "A Time and Area Limited Epidemic Forwarding Method for Alleviating Vehicular Traffic Congestion," The Smart Computing Review, Jun. 2012.

[17]. R. Arnott, "A bathtub model of downtown traffic congestion," Journal of Urban Economics, vol. 76, pp. 110-121, Jul. 2013.

[18]. W. Sun, D. Guo, Q. Li, and H. Fang, "School runs and urban traffic congestion: Evidence from China," Regional Science and Urban Economics, vol. 86, p. 103606, Jan. 2021.

[19]. M. Wang and N. Debbage, "Urban morphology and traffic congestion: Longitudinal evidence from US cities," Computers, Environment and Urban Systems, vol. 89, p. 101676, Sep. 2021.

[20]. A.Stathopoulos and M. G. Karlaftis, "Modeling Duration of Urban Traffic Congestion," Journal of Transportation Engineering, vol. 128, no. 6, pp. 587-590, Nov. 2002. 